\title{
The Art of Improvising: The Be-Bop Language and the Dominant Seventh Chords
}

\author{
Carmine Cataldo \\ Mechanical Engineering, Battipaglia, Italy \\ Email: catcataldo@hotmail.it
}

How to cite this paper: Cataldo, C. (2017). The Art of Improvising: The Be-Bop Language and the Dominant Seventh Chords Art and Design Review, 5, 181-188. https://doi.org/10.4236/adr.2017.53014

Received: July 24, 2017

Accepted: August 11, 2017

Published: August 14, 2017

Copyright $\odot 2017$ by author and Scientific Research Publishing Inc. This work is licensed under the Creative Commons Attribution International License (CC BY 4.0).

http://creativecommons.org/licenses/by/4.0/

\begin{abstract}
The aim of this article lies fundamentally in illustrating the first part of a simple and intuitive method, finalized to "speaking" the Be-Bop language immediately, without possessing any jazz background whatsoever. The main peculiarity of the method consists in the fact that the attention of the improviser is always focused on Triads. We herein exclusively discuss the improvisation techniques regarding the dominant seventh chords. Starting from a specific extended "sentence", built around the Major Triad, we show how to instantly deduce further sentences, how to modify them, by cutting and adding "words", and how to effectively combine them.
\end{abstract}

\section{Keywords}

Jazz Improvisation, Be-Bop, Fast Learning, Triads, Dominant Seventh Chords

\section{Introduction}

We herein exclusively deal with the dominant seventh chords, starting from a fundamental extended "sentence", built around the major triad that immediately gives birth to three further sentences. The sentences so obtained can be easily cut, modified, by using new "words" (Wise, 1983) and extensions, and then combined.

Basically, the peculiarity of the method lies in the fact that the attention of the improviser is always focused on the triad. On this subject, we reveal in advance that the above-mentioned peculiarity apparently loses its importance when the (minor) seventh and the ninth are introduced. Actually, the integrity of the method can be effectively preserved by learning to locally focus the attention no longer on the major triad, but rather on the minor one placed a perfect forth higher (with respect to the root of the dominant seventh chord we are considering). Anyway, we will discuss this particular in the "Final Remarks and Conclusion" section. 


\section{The Method}

\subsection{The Fundamental "Sentence"}

We here in will deal with a $C 7$ chord. Obviously, the method should be practiced and mastered in all 12 keys.

Although it is anything but a novelty (Wise, 1983), we will carry out the whole discussion in terms of sentences and words. Before starting, it is worth underlining how the only required background actually consists in the mere knowledge of Triads.

The fundamental sentence we have to start from is shown in Figure 1.

In Figure 1, like in all the staves in this paper (net of a single exception), the chordal notes (meant as the notes that constitute the triad) are depicted in red.

The fundamental sentence, intentionally extended along two adjacent octaves, allows playing, all at once, all the altered tensions $(b 13, \# 11, \# 9, b 9)$ of the chord.

\subsection{Learning to "See" the Major Triad}

The fundamental sentence can be evidently played starting from each of the chordal notes, by means of a simple translation.

It is essential to underline that, in playing both the sentence we have just examined and the ones that will arise from it, the musician must focus his/her attention "exclusively" on the major triad and its inversions (in case of translation).

From the pattern shown in Figure 1, exploiting the translation and carrying out a banal cutting, we immediately deduce the three following sentences:

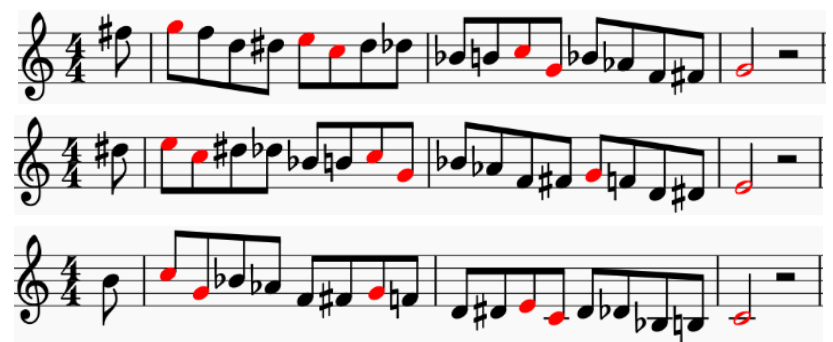

The ascending (chromatic) approach that appears in the anacrusis is optional.

Although the topic is not herein properly addressed, we highlight how the sentences in Staves (1), (2), and (3) lend themselves to several metric displacements.

At this point, it is worth practicing an exercise, simple and useful, based upon the major triad and the ascending (chromatic) approach:
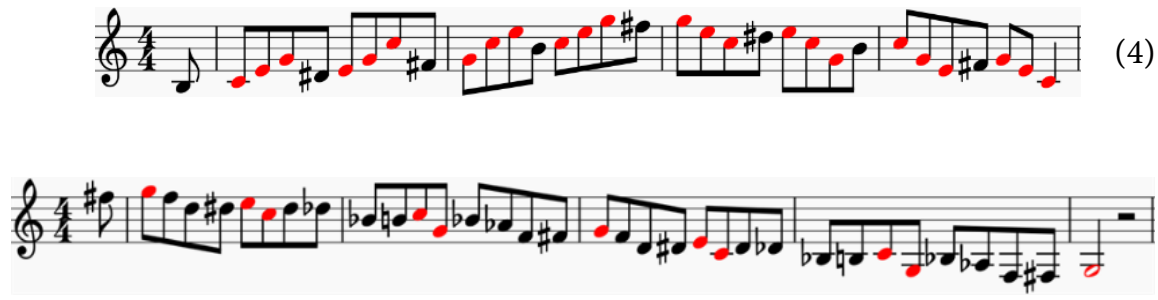

Figure 1. The fundamental "Sentence". 
From Staves (1), (2), and (3), imposing a banal metric displacement and exploiting the previous exercise, we deduce the three following sentences:

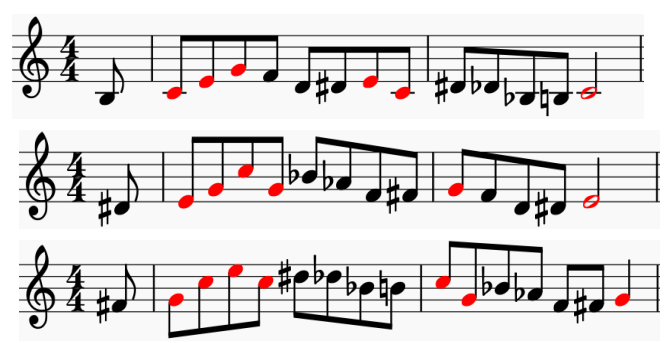

At this point, we can already start to combine the sentences deduced, so as to obtain something more complex (Baker, 1988a, 1988b, 1988c, 1988d; Wise, 1983).

For example, from Staves (5), (6) and (7), the latter transposed an octave higher, we can easily deduce the underlying long sentence:

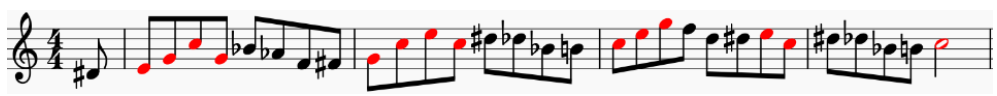

Let's now practice the following pattern, based upon the mixed approach concept:

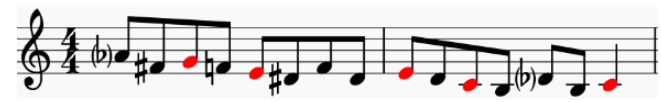

The previous sentence, especially if we consider the optional accidentals in brackets, allows the musician to sound very "chromatic".

Obviously, coherently with what highlighted at the beginning of this section, in performing the exercise proposed in Staff (9), the improviser must focus his/her attention "exclusively" on the major triad.

We can clearly continue to melt the sentences, now with an additional ingredient.

For example, from Staves (2) and (9), the latter transposed an octave higher, we immediately obtain:

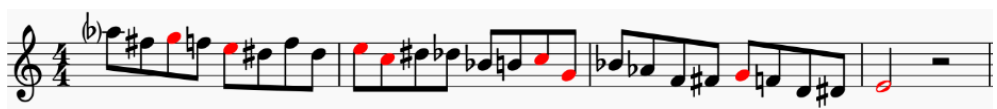

Let's now consider the following new word, nothing but a very short "back and forth" chromatic bridge between the fifth and the sixth:

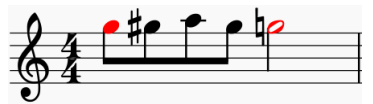

Obviously, our attention must be exclusively focused on the fifth.

Exploiting the word just considered, we obtain a great deal of new sentences.

For example, from Staff (1), with an extension to the third, and Staff (11) we obtain:

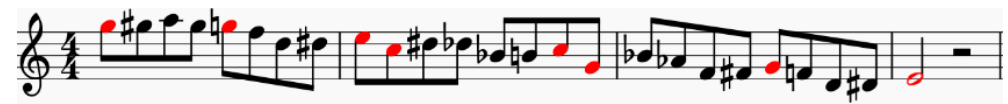

\subsection{Introducing the (Minor) Seventh}

Let's consider the following new word that simply consists in a descending 
chromatic bridge between the minor seventh (depicted in green) and the fifth:

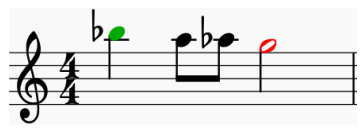

From Staff (1), with an extension to the third, and Staff (13) we obtain:

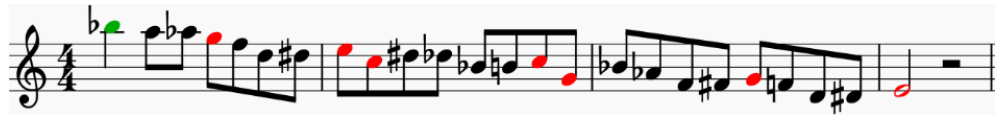

By juxtaposing Staves (11) and (13) we deduce the underlying new word:

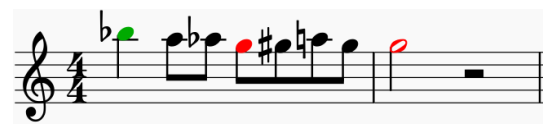

Exploiting the word we have just obtained, from Staff (1), with the usual extension to the third, we deduce the following sentence:

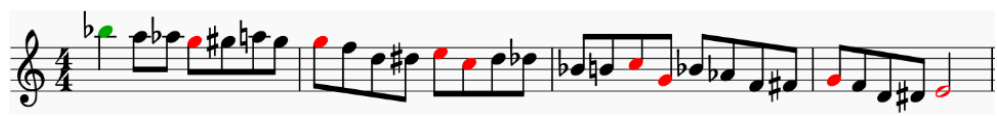

Now, let's abandon for a while the seventh. The sentence proposed in Staff (1) may be modified by using a short cut, nothing but a descending chromatic bridge that links the third to the root:

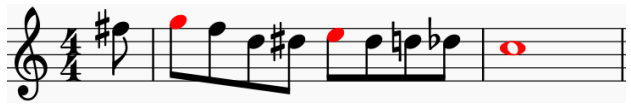

It is worth noting how the prior sentence can be evidently played considering an Fmaj7 chord on the last bar.

From Staves (11) and (17), bearing in mind that the ascending (chromatic) approach that appears in the anacrusis is optional, we immediately obtain:

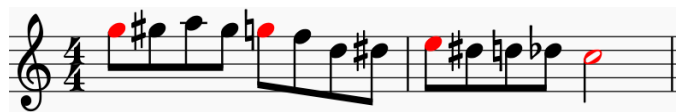

Recovering the seventh, from Staves (13) and (17) we deduce the following:

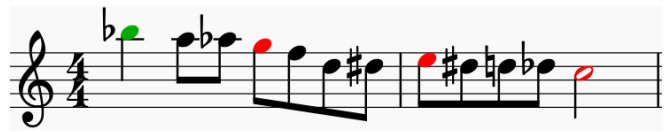

Similarly, from Staves (15) and (17) we have:

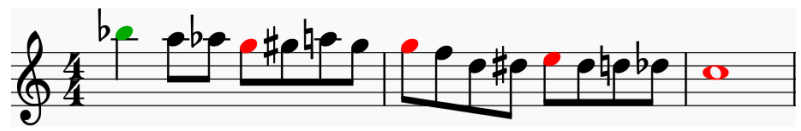

It is worth noticing how the sentence we have just obtained can be evidently played on the $G-7 / C 7 / F m a j 7$ harmonic progression.

The sentence in Staff (1) can be further modified by means of a deviation. Very simply, once reached the third, instead of playing the sentence the way it was initially conceived, we start moving along the well-known Be-Bop dominant scale, until we reach the minor seventh:

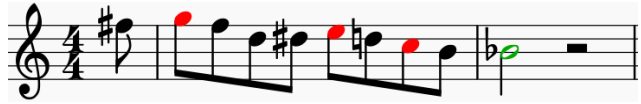

From Staves (11) and (21) we have: 


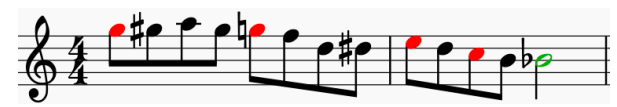

From Staves (13) and (21) we have:

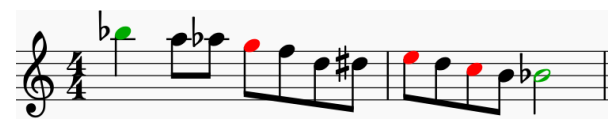

From Staves (15) and (21) we have:

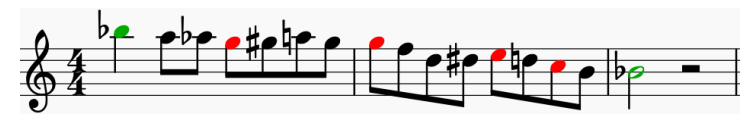

If we extend the foregoing sentence along two consecutive octaves, we obtain a new long sentence, in which the role of the root is now played, if we can say so, by the minor seventh.

Following the same procedure we have exploited in order to deduce Staves (1), (2), and (3), the new sentence, shown in Figure 2, instantly gives birth to three further sentences, omitted for brevity that can be progressively modified in the usual way.

At this point, we can already build a great number of new sentences, so covering a large portion of the "Be-Bop vocabulary" (Baker, 1988a, 1988b, 1988c; Wise, 1983).

For example, by opportunely overlapping Staves (6), (21), and (23), the latter transposed an octave lower and stopped once reached the third, we obtain:

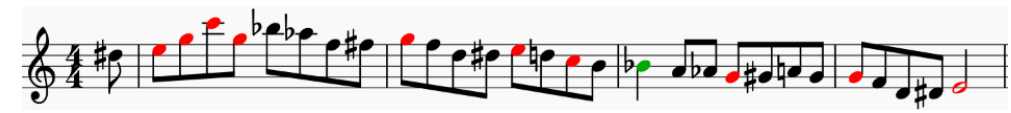

Obviously, further modifications, no matter how significant they may be, allow to considerably increase the number of possibilities. Suffice it to consider that the chromatic bridge introduced in Staff (17) can be also bidirectional.

In the light of the previous remark, exploiting the deviation considered in Staff (21), we deduce the following interesting new sentence:

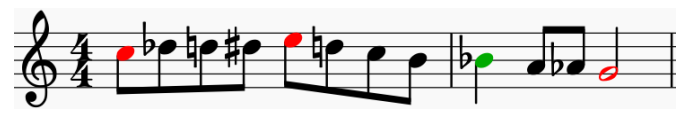

From Staves (8) and (26), acting in the usual way, we have:

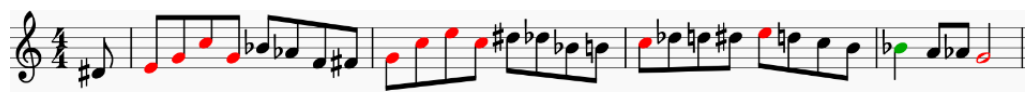

\subsection{Introducing the Ninth}

For the sake of brevity, in this section, since the method should be clear enough by now, the writing of the single words is intentionally omitted.

Firstly, we can build a simple descending chromatic bridge between the ninth, and the minor seventh (both are depicted in green).

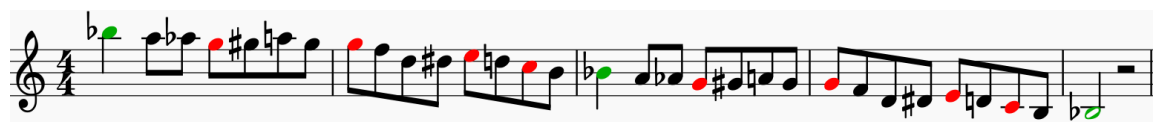

Figure 2. Another useful "Sentence". 
If we exploit such a procedure, from the sentence in Staff (24), transposed an octave lower and extended to the fifth, we deduce the following sentence:

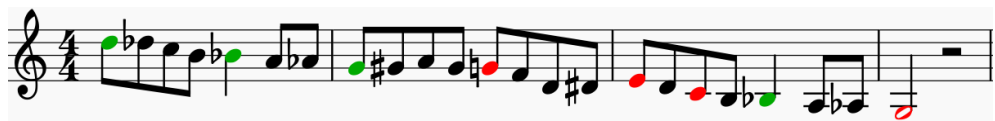

We can also build "back and forth" chromatic bridges: the simpler, obviously, is the one that involves the ninth and the tenth (the third an octave higher).

From Staves (20) and (28), for example, we obtain:

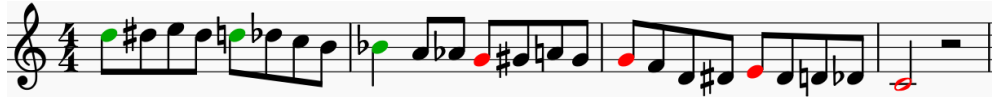

The most interesting "back and forth" chromatic bridge is the one that involves the minor seventh and the ninth.

From Staff (28), for example, we deduce the underlying sentence:

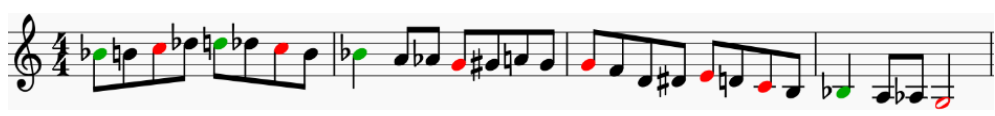

\subsection{How to Enrich a Sentence (a Very Short Outline)}

As soon as the improviser becomes reasonably able to master the method, an enrichment phase can finally start. Although the procedure is not herein addressed, we can simply state that the easiest way to enrich a sentence consists in using "repetitions" and "diatonic oscillations" (Garland, 1999; Kelly, 2013; Powell, 1998, 2002).

A simple example of enrichment, fully based on the sentence deduced in Staff (30), is shown in Figure 3.

\section{Final Remarks and Conclusion}

In the Be-Bop language, the dominant seventh chords are very often replaced by diminished chords (Parker, 1978) built on the third, the fifth, the minor seventh, or the flat ninth. On this subject, it is surely worth practicing the following exercise:

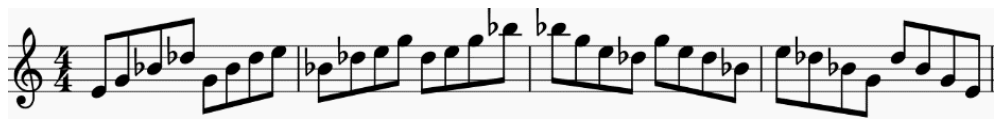

By exploiting the diminished substitution (Levine, 2009), we can further modify the sentences obtained up until now. Let's provide just a couple of useful examples (the flat ninth is intentionally depicted in orange).

From Staff (24), we can easily deduce the following sentence:

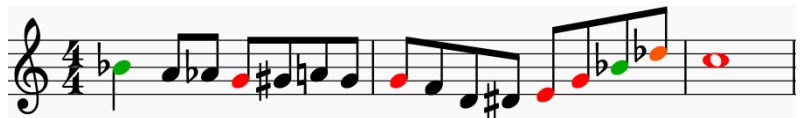

From Staff (28), without the "back and forth" chromatic bridge on the fifth, we have:

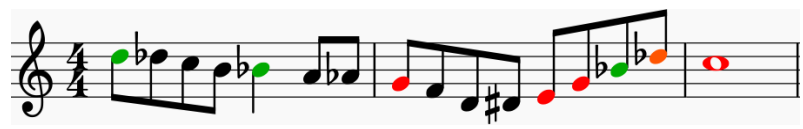




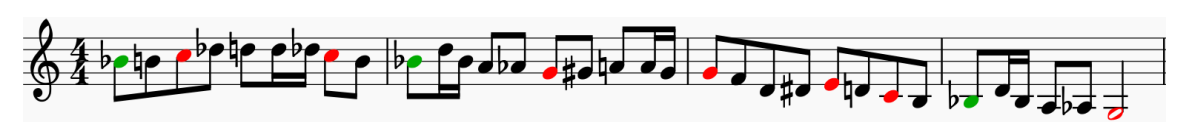

Figure 3. How to enrich a "Sentence".

The last two sentences can be evidently played on the $G-7 / C 7 / F m a j 7$ harmonic progression. This is not a coincidence: on the contrary, we are finally given the opportunity to qualitatively explain the reason why, notwithstanding the introduction of non-chordal notes (minor seventh and ninth), the method may still be considered as being exclusively based on triads. In the first bar of Staff (33), for example, the attention of the improviser must no longer be focused on the $C$ major triad, but rather on the $G$ minor triad. On this subject, we can state that, to a certain extent, $C 7$ may be treated as if it were $G-7$ (both chords have a diatonic relation with $E-7 b 5$ ). Consequently, the improviser can serenely play on $C 7$ almost all the sentences suitable for $G-7$ (herein not discussed), and vice-versa, with very few exceptions, so considerably enlarge the language.

Obviously, this method constitutes nothing but a simplified introduction to the Be-Bop language: in fact, we have intentionally avoided to investigate the employment of several very effective scales (hexatonic, such as the whole-tone scale, heptatonic, such as the super-Locrian, octatonic, such as the halftonetone), "public domain" patterns (Coker et al., 1982; Nelson, 2010), and tritone substitutions (Levine, 2009).

\section{Acknowledgements}

This paper is dedicated to my mother, Giuseppina, who has always encouraged me to play piano with passion and devotion.

I would like to thank my friends Francesco D'Errico, Giulio Martino, and Sandro Deidda, excellent Italian jazz musicians and esteemed teachers at the Conservatory of Salerno, for their precious suggestions.

\section{References}

Baker, D. (1988a). How to Play Bebop (Volume 1). Los Angeles, CA: Alfred Publishing Co. Inc.

Baker, D. (1988b). How to Play Bebop (Volume 2). Los Angeles, CA: Alfred Publishing Co. Inc.

Baker, D. (1988c). How to Play Bebop (Volume 3). Los Angeles, CA: Alfred Publishing Co. Inc.

Baker, D. (1988d). Jazz Improvisation. Los Angeles, CA: Alfred Publishing Co. Inc.

Coker, J., Casale, J., \& Campbell, G. (1982). Patterns for Jazz-A Theory Text for Jazz Composition and Improvisation. Los Angeles, CA: Alfred Publishing Co. Inc.

Garland, R. (1999). The Jazz Piano Solos of Red Garland (by Tony Genge). Houston, TX: Houston Publishing.

Kelly, W. (2013). The Wynton Kelly Collection: 25 Solo Transcriptions (by Michael Miller). New Albany, IN: Jamey Aebersold Jazz.

Levine, M. (2009). The Jazz Theory Book (Italian Edition by F. Jegher). Milan: Curci Jazz. 
Nelson, O. (2010). Patterns for Improvisation. New Albany, IN: Jamey Aebersold Jazz.

Parker. C. (1978). Charlie Parker Omnibook. Los Angeles, CA: Atlantic Music Corporation.

Powell, B. (1998), Bud Powell Classics (Artist Transcriptions). Milwaukee, WI: Hal Leonard.

Powell, B. (2002). The Bud Powell Collection: Piano Transcriptions (Artist Transcriptions). Milwaukee, WI: Hal Leonard.

Wise, L. (1983). Bebop Bible-The Musicians Dictionary of Melodic Lines. REH Publications (Distributed by Columbia Pictures Publications).

Submit or recommend next manuscript to SCIRP and we will provide best service for you:

Accepting pre-submission inquiries through Email, Facebook, LinkedIn, Twitter, etc. A wide selection of journals (inclusive of 9 subjects, more than 200 journals)

Providing 24-hour high-quality service

User-friendly online submission system

Fair and swift peer-review system

Efficient typesetting and proofreading procedure

Display of the result of downloads and visits, as well as the number of cited articles

Maximum dissemination of your research work

Submit your manuscript at: http://papersubmission.scirp.org/

Or contact adr@scirp.org 